\title{
Circuitos locales en contextos globales de circulación. Una aproximación a las revistas científicas argentinas
}

Local circuits in global contexts of circulation. An overview of Argentine scientific journals

\author{
Maximiliano Salatino \\ Universidad Nacional de Cuyo, Argentina \\ maxisalatino@gmail.com
}

\section{RESUMEN:}

Las revistas científicas se han consolidado como parte neurálgica de los regímenes de evaluación de la ciencia contemporánea. En este contexto, nos interesa aproximarnos a un espacio de circulación nacional concreto para advertir hasta qué punto la tan remanida globalización de la ciencia ha impactado en circuitos locales y regionales. En este artículo nos proponemos indagar la morfología del espacio argentino de revistas científicas, su constitución histórica y actual mapeo espacio-institucional. Para ello analizamos un universo de 1208 revistas científicas indexadas y no indexadas activas al año 2016/2017. Como resultado observamos la coexistencia de diferentes formas simultáneas y diversas de circulación de revistas. Particularmente analizamos dos tipos particulares de circuitos orientados localmente: 1) un circuito con una larga tradición de edición, orientado disciplinarmente por las ciencias exactas y naturales, editados mayoritariamente en papel y sin indexación; 2) y otro, con una tradición de edición desde mediados de 1990, que edita digitalmente y se desarrolla en el seno de grandes universidades nacionales. Proponemos una conceptualización guiada por la noción de capital social para comprender la subsistencia de estos circuitos locales en el marco de las culturas evaluativas nacionales y de la competencia científica internacional.

Palabras clave: Revistas científicas argentinas, Circuitos locales, Competencia científica, Universidades nacionales, Capital social.

\section{Abstract:}

Scientific journals are a neuralgic part of contemporary science assessment regimes. In this context, we are interested in approaching a space of concrete national circulation to realize to what extent the globalization of science has affected local and regional circuits. In this article, we propose to investigate the morphology of the Argentine space of scientific journals, its historical constitution and current space-institutional mapping. To this end, we analyze a universe of 1208 indexed and non-indexed scientific journals active as of 2016/2017. As a result, we observe the coexistence of different simultaneous and diverse forms of journal circulation. In particular, we analyzed two types of locally oriented circuits: 1 ) one with a long publishing tradition, oriented by natural and exact disciplines, mostly published on paper and without indexing; 2) and another, with a publishing tradition since the mid-1990s, which edits digitally and is carried out in the heart of large national universities. We propose a conceptualization guided by the notion of social capital to understand the subsistence of these local circuits within the framework of national evaluative cultures and international scientific competition.

KEYWORDS: Argentine scientific journals, Local circuits, Scientific competition, National universities, Social capital.

\section{INTRODUCCIÓN}

Amplias son las discusiones que se sostienen en el mundo académico asociadas a las publicaciones periódicas y su rol en la práctica de los/as agentes científicos/as. Conocemos por los estudios disponibles su incidencia en los regímenes de evaluación (Alperin et al., 2019; Beigel, 2014; Bianco, Gras, y Sutz, 2016; Mckiernan, Schimanski, Nieves, Niles, y Alperin, 2019), la búsqueda por generar espacios de visibilidad (De-Filippo, 2013; Leta, Thijs, y Glänzel, 2013; Rozemblum, 2014), la crítica al productivismo (Machado y Bianchetti, 2011; Velho, 1986; Vessuri, 1987; Zuin y Bianchetti, 2015), los desafíos que presentan las 
modalidades del publish or perish (Aguado-López y Becerril-García, 2016; Leite, Pinho, Miorando y Caregnato, 2018; Hanafi, 2011; Liu, Hu, Wang, y Shi, 2018; Salager-Meyer, 2014), y su transformación contemporánea dada las tecnologías de la información y comunicación (Alperin, Fischman, y Willinsky, 2008; Chan, Kirsop, y Arunachalam, 2011; Guédon, 2009; Minniti, Santoro, y Belli, 2018).

Los debates son diversos, en especial, por la injerencia que poseen las estrategias de publicación en las formas en que la ciencia se produce, inclusive desde el momento de iniciar un proyecto académico de investigación. Allí entran en consideración cuestiones como la indexación, el factor de impacto, el/a editor/ a, las líneas editoriales, el idioma de publicación, entre otros. Incluso la estrategia de publicación modifica, transforma y adecua el proceso de producción de conocimiento científico. Estos fenómenos nos permiten pensar a las revistas científicas insertas en las dinámicas del mundo editorial y de los campos científicos nacionales.

La edición de revistas científicas ha sido un rasgo destacado en los procesos de institucionalización de las ciencias en América Latina. Muchos estudios de institucionalización y profesionalización mencionan la edición de revistas como un rasgo de maduración de las disciplinas, un instrumento de circulación local de conocimiento científico y como la consolidación de líneas teóricas afincadas en políticas editoriales (Ansaldi, 1991; Beigel, 2010, 2013). En este sentido, proponemos una mirada sobre las publicaciones periódicas que incluyen los aspectos anteriormente señalados pero que, además, incorpora una mirada sobre la transformación de las revistas científicas en el contexto de globalización de la competencia científica.

En su artículo acerca del campo científico de 1976 publicado en las Actes de la recherche en sciences sociales, Bourdieu afirmó que los instrumentos de difusión de la ciencia, particularmente las revistas científicas, ejercen una influencia muy importante a las esferas de la consagración científica. La asociación realizada por el autor francés se vinculaba directamente con la distinción entre lo que se publica y lo que no. Este es un punto nodal, lo que circula no es todo lo producido sino aquello que ha sido publicado. La ciencia es ciencia publicada y en este contexto, las revistas científicas forman parte de un sistema de selección. En este sentido, la "distinción" en los campos científicos se vincula con las formas de (re)conocimiento y de visibilidad. Según Bourdieu, la visibilidad representa el valor diferenciado del capital científico que logra separar el nombre propio del autor de su misma contribución. Este ejercicio de visibilización ejerce un poder de reconocimiento que se encuentra en la base de la acumulación de este capital simbólico específico, "el científico aporta una contribución, que le es reconocida por unos actos de reconocimiento público, por ejemplo, la referencia en forma de cita de las fuentes del conocimiento utilizado" (Bourdieu, 2003, p.101).

La discusión contemporánea señala a las bases de datos e indexadoras como la infraestructura de la comunicación científica en América Latina (Alperin, Babini y Fischman, 2014; Babini y MachinMastromatteo, 2015; Delgado-Troncoso y Fischman, 2014). Estos estudios indican la importancia de esas bases de datos como soporte de revistas, artículos y otros productos académicos. En este trabajo, nos orientamos en cambio a considerar el peso que poseen las instituciones editoras como articulaciones científico-políticas sin las cuales no podríamos considerar la estructuración de un espacio regional o nacional. En especial, pensamos en el rol que poseen las universidades nacionales como las instituciones que mayor cantidad de revistas editan en la Argentina (41\%).

Es importante también considerar qué efectos tuvieron y aún tienen las políticas de comunicación científica internacionales en los campos científico-universitarios nacionales. En el caso argentino, la existencia de culturas evaluativas enfrentadas, lógicas diferenciadas entre docencia e investigación y cierto grado relativo de autonomía frente a patrones y criterios mainstream de publicación nos orienta a analizar nacional y localmente estas relaciones estructurantes (Beigel, 2015). La circulación de revistas científicas posee diversas direccionalidades y escalas de circulación. Una misma revista puede estar local, regional y/ o internacionalmente orientada según el idioma en que se publique, la disponibilidad a texto completo de su contenido, el soporte de publicación y su indexación. Es decir, podemos observar la presencia de estrategias de circulación que llevan a determinadas revistas a ser completamente editadas en inglés con el fin de dialogar con espacios de corriente principal. Al mismo tiempo, podemos señalar revistas que se editan 
en español, en papel y que poseen circulación restringida. Entre estos dos polos, observamos revistas que circulan a nivel nacional y/o regional con estrategias de circulación multiescalares que responden a regímenes de evaluación diferenciados, como puede ser el caso de Consejo Nacional de Investigaciones Científicas y Técnicas (CONICET), PROINCE (Programa de Incentivos para Docentes Investigadores de la Secretaría de Políticas Universitarias) o los concursos docentes en universidades nacionales en Argentina.

Nos interesa en este trabajo analizar históricamente la constitución de un espacio argentino de revistas científicas en sintonía con un mapeo institucional de la edición. Conocemos por estudios previos algunos rasgos generales de la expansión de la publicación científica en América Latina (Salatino, 2018a), lo que nos permite aquí destacar la larga tradición editorial argentina de revistas científicas y la consolidación de espacios locales de visibilización de conocimiento científico. En este sentido, nos interesa plantear interrogantes que recorrerán todo el trabajo: ¿Cuál es la infraestructura que permite que las revistas científicas circulen en Argentina? ¿Qué tipo de circuitos existen? ¿Y qué relación tienen los circuitos con los sistemas de evaluación vigentes?

Para avanzar sobre estos interrogantes, proponemos analizar empíricamente las revistas universitarias en el marco del universo de 1208 revistas científicas argentinas con actividad de publicación a los años 2016/17 . El objetivo principal fue planteado a partir de la inclusión de todas las revistas científicas (excluyendo las de divulgación), aun las que no se encuentran indexadas en las bases regionales (SciELO, RedALyC y Latindex Catálogo), en las internacionales de corriente principal (Web of Science y Scopus) o en acceso abierto (DOAJ). Este universo nos permitió advertir toda una serie de revistas editadas en papel o en algún formato digital, con una larga tradición y ancladas en universidades nacionales. Pudimos así detectar que el 34\% del universo de revistas no se encuentran indexadas, porcentaje que aumenta al 55\% si excluimos al Catálogo de Latindex que fue una base indexadora muy importante para las revistas argentinas, pero actualmente se encuentra en proceso de recatalogación. Además, observamos que el 54\% sólo se editan en papel. Estos rasgos generales nos permiten preguntarnos, ¿̨por qué aún se editan revistas en papel, o sin indexar o con estrategias de circulación que no se corresponden con la presión por la indexación o la digitalización?

El artículo se divide en tres secciones. En un primer momento, contextualizamos históricamente la edición de revistas en Argentina. Trazamos aquí líneas interpretativas ligadas a las disciplinas, los soportes de edición y la indexación. En un segundo momento, profundizamos el análisis en las quinientas revistas universitarias argentinas lo que nos permite conceptualizar sus dinámicas de circulación, direccionalidades y estrategias de consagración guiadas por las culturas evaluativas nacionales. En la última sección, analizamos la circulación de las revistas universitarias, en especial los circuitos locales, resaltando su diversidad y vinculaciones con los soportes de edición, el idioma de publicación, la disponibilidad de sus contenidos a texto completo y la indexación.

\section{Morfología HistóRiCA DE LA CIRCULACión DE REVISTAS ARgENTINAS}

En América Latina se han desarrollado redes y espacios editoriales de revistas científicas desde finales del siglo XVIII y principios del XIX. Es decir, la región cuenta con una larga tradición editorialista que ha tenido períodos de emergencia, expansión y consolidación. Sin la contextualización de la larga tradición editorialista latinoamericana es difícil pensar las políticas editoriales y la circulación de revistas en la actualidad. Muchas revistas, instituciones editoras y colectivos editoriales que actualmente editan publicaciones periódicas en Argentina y América Latina forman parte de un espacio de circulación que en muchos casos podemos reconocer como previo a la institucionalización y profesionalización de las ciencias.

En este contexto, nos encomendamos a caracterizar la composición morfológica actual del espacio argentino de circulación a partir del análisis de sus rasgos más estructurales. El análisis propuesto nos muestra una fotografía del estado actual de la edición argentina. En nuestra base de datos contamos con publicaciones periódicas activas creadas desde 1858 hasta el año 2016/2017. Esto marca un claro vector de análisis asociado 
con la existencia de una larga tradición de edición y con la adecuación de una revista a diferentes tiempos y procesos históricos. En especial, las trayectorias editoriales se ven constreñidas por las reglas de la competencia científica a escala local, regional e internacional.

Hemos adoptado una periodización en la cual se entrecruzan criterios cuantitativos de expansión y consolidación de edición de revistas, aspectos institucionales y de política editorial y procesos de profesionalización de la circulación (Salatino, 2018a). Es así como identificamos cuatro grandes períodos en la estructuración del espacio latinoamericano de revistas científicas:

- El asociacionismo editorialista (1772-1964). Este largo período se enmarca en la emergencia de las primeras revistas latinoamericanas, el preponderante rol de las asociaciones científicas como instituciones editoriales y la constitución del espacio intelectual regional. Ya en las primeras décadas del siglo XX, el asociacionismo se vio inserto en el interesante proceso de profesionalización e institucionalización de las ciencias en América Latina y su creciente diferenciación de los campos intelectuales tradicionales ligados al ensayismo y el análisis histórico. El período tiene como fecha de inicio -1772- el año de la primera revista registrada en la región, el Mercurio Volante editado en México. Y como finalización, 1964, año el cual se desarrolló en el Universidad de Puerto Rico Rio Piedras la primera reunión latinoamericana de diagnóstico, análisis y evaluación de revistas científicas.

- La documentación (1951-1980). Este período marca una fuerte profesionalización del espacio regional de revistas. Se promocionaron fuertemente desde la UNESCO, la OEA y la UNAM espacios de formación, profesionalización y evaluación de la edición. En 1951 se creó con sede en la UNAM y fue promocionado por la UNESCO el primer centro de documentación de información científica de América Latina, a partir del cual se regionalizó la necesidad y urgencia de generar sistemas de documentación en las grandes universidades nacionales. En 1980 se creó la Bibliografía Latinoamericana, base que buscó dar cuenta de toda la producción latinoamericana, lo que se plantea como un antecedente fundamental en la visibilización del conocimiento científico producido en esta parte del mundo.

- Regionalización (1970-2002). A partir de la década de 1970 podemos observar en la región la estructuración de un espacio de revistas científicas. Es decir, ya para esta época se cuenta con índices, bibliografías y estudios programáticos sobre la producción latinoamericana. En 1970, la UNAM desarrolló los primeros tres sistemas de citación latinoamericanos, CLASE, PERIODICA y ALERTA. Buena parte de las revistas latinoamericanas se desarrollaron en un contexto de regulación de las prácticas editoriales, con una presencia importante de la revisión de pares para garantizar la calidad de las producciones y con la adecuación de las revistas a criterios estandarizados de calidad editorial.

Se ha dividido este período en dos sub-etapas: expansión hasta 1994 y consolidación hasta el 2002. Concretamente, el espacio de revistas tuvo una expansión muy importante durante la década de 1980 que tuvo como eje principal la incorporación de las tecnologías de la comunicación y la información. En los noventa, se crearon las principales bases regionales que permitieron conocer, acceder y visibilizar la ciencia producida en la región publicada en revistas científicas. El proyecto Latindex, pionero en la consolidación de la regionalización emergió a partir de la realización del Taller de Guadalajara en 1994. Luego se fundará SciELO en 1998 y RedALyC en 2003.

- Internacionalización (1999-). El último período refiere a una etapa del espacio regional en la cual se profundizó la tensión entre una tendencia latinoamericanista de circulación y una orientación a la corriente principal. Es decir, se inició un proceso en el cual paulatinamente se favoreció la adopción de criterios restrictivos, foráneos y exclusivos en la evaluación de las revistas, de los artículos y de las culturas evaluativas a nivel de los campos científicos latinoamericanos. Este período también posee dos sub-etapas. Una primera ligada a la extensión del formato digital por sobre el papel en 
la circulación regional lo que permitió avanzar en la consolidación de la visibilidad y el acceso de las revistas latinoamericanas. En este punto, la emergencia de SciELO en 1998 marcó un antes y después. SciELO fue la primera base latinoamericana en donde se pudo acceder a texto completo a las producciones insertas en sus colecciones. En la segunda sub-etapa, podemos observar una internacionalización más heterónoma y también se encuentra guiada por un ejemplo brasileño. En 2007, el gobierno brasileño lanzó Qualis, un sistema de clasificación de revistas científicas que permite la diferenciación en estratos. Qualis sirve para guiar los procesos de evaluación de programas de posgraduación y proyectos de financiamientos en Brasil. Esto implicó un fuerte rasgo en el espacio regional en el cual se profundizó una tendencia guiada por la adopción de la indexación, los índices de impacto y la clasificación de revistas en la (e)valuación de la ciencia publicada en América Latina.

La tabla 1 permite observar que la creación de revistas en Argentina tiene importantes analogías con el desarrollo del espacio latinoamericano de revistas científicas. Particularmente, señalamos el grupo de revistas editadas a partir del período del asociacionismo y documentación (alrededor del 12\% del total) que continúan publicando en el siglo XXI. En el período de regionalización se manifiesta un aumento significativo en términos absolutos de revistas que tendrá un ritmo de normalización durante el periodo de internacionalización. Es importante destacar el rol de las políticas de acceso abierto adoptadas en Argentina, en particular, y en América Latina en general, en el cual se propicia la circulación, visibilidad y acceso al conocimiento científico publicado en revistas sin costo para las audiencias y los/as autores/as.

TABLA 1

Cantidad de revistas creadas por períodos ${ }^{2}$

\begin{tabular}{|l|c|c|c|c|}
\hline \multicolumn{2}{|c|}{ Periodos } & Años & $\begin{array}{c}\text { Q revistas } \\
\text { ALyC }\end{array}$ & $\begin{array}{c}\text { Q revistas } \\
\text { argentinas }\end{array}$ \\
\hline Asociacionismo & Editorialismo & $1838-1950$ & 363 & 76 \\
\hline Documentación & Profesionalización & $1951-1970$ & 532 & 76 \\
\hline Regionalización & Expansión & $1971-1994$ & 2511 & 275 \\
\cline { 2 - 5 } & Consolidación & $1995-2002$ & 2771 & 286 \\
\hline Internacionalización & Digitalización & $2003-2008$ & 2092 & 243 \\
\cline { 2 - 5 } & Heteronomía & $2009-2015$ & 1835 & 252 \\
\hline Totales & -- & -- & 10104 & 1208 \\
\hline
\end{tabular}

Fuente: elaborada por el autor.

Las revistas activas más antiguas de nuestra base de datos son editadas por organismos de la sociedad civil y sociedades científicas, en clara sintonía con el período de asociacionismo editorialista. La más antigua es la revista farmacéutica de 1858 editada por la Academia Nacional de Farmacia y Bioquímica, posteriormente se fundaron la Revista del Museo Argentino de Ciencias Naturales (1864), la Revista de la Academia Nacional de Ciencias de la República Argentina (1875), los Anales de la Sociedad Científica Argentina (1876), La Ingeniería (1879) editada por el Centro Argentino de Ingenieros y la Revista de la Asociación Médica Argentina de 1892. El asociacionismo fue la infraestructura de circulación que permitió un creciente proceso de publicación científica en Argentina que tuvo un reflejo importante en la creación de revistas culturales, ensayísticas e intelectuales de finales del siglo XIX.

Si observamos la distribución relativa de la fecha de creación de las revistas en función de su adscripción a gran área disciplinar (figura 1) podemos identificar un vector claro orientado por las ciencias físiconaturales, exactas y médicas desde las primeras décadas del siglo XX hasta aproximadamente 1960. La 
consolidación de las revistas argentinas tuvo como referente a revistas como El Hornero; Journal of the Argentine Chemical Society; Darwiniana; Archivos Argentinos de Pediatría; Revista Argentina de Cardiología; Medicina (Buenos Aires); Acta Physiologica Pharmacologica et Therapeutica Latinoamericana; Phyton (Buenos Aires); Ameghiniana; Acta Psiquiátrica y Psicológica de América Latina; Acta Bioquímica Clínica Latinoamericana; entre otras. Todas ellas revistas que se editan en la actualidad, por lo que poseen una larga tradición editorial y una adaptación a las reglas de la competencia científica internacional ya que se encuentran indexadas en bases de datos de la corriente principal como Web of Science o Scopus.

FIGURA 1

Creación de revistas argentinas según período y área disciplinar

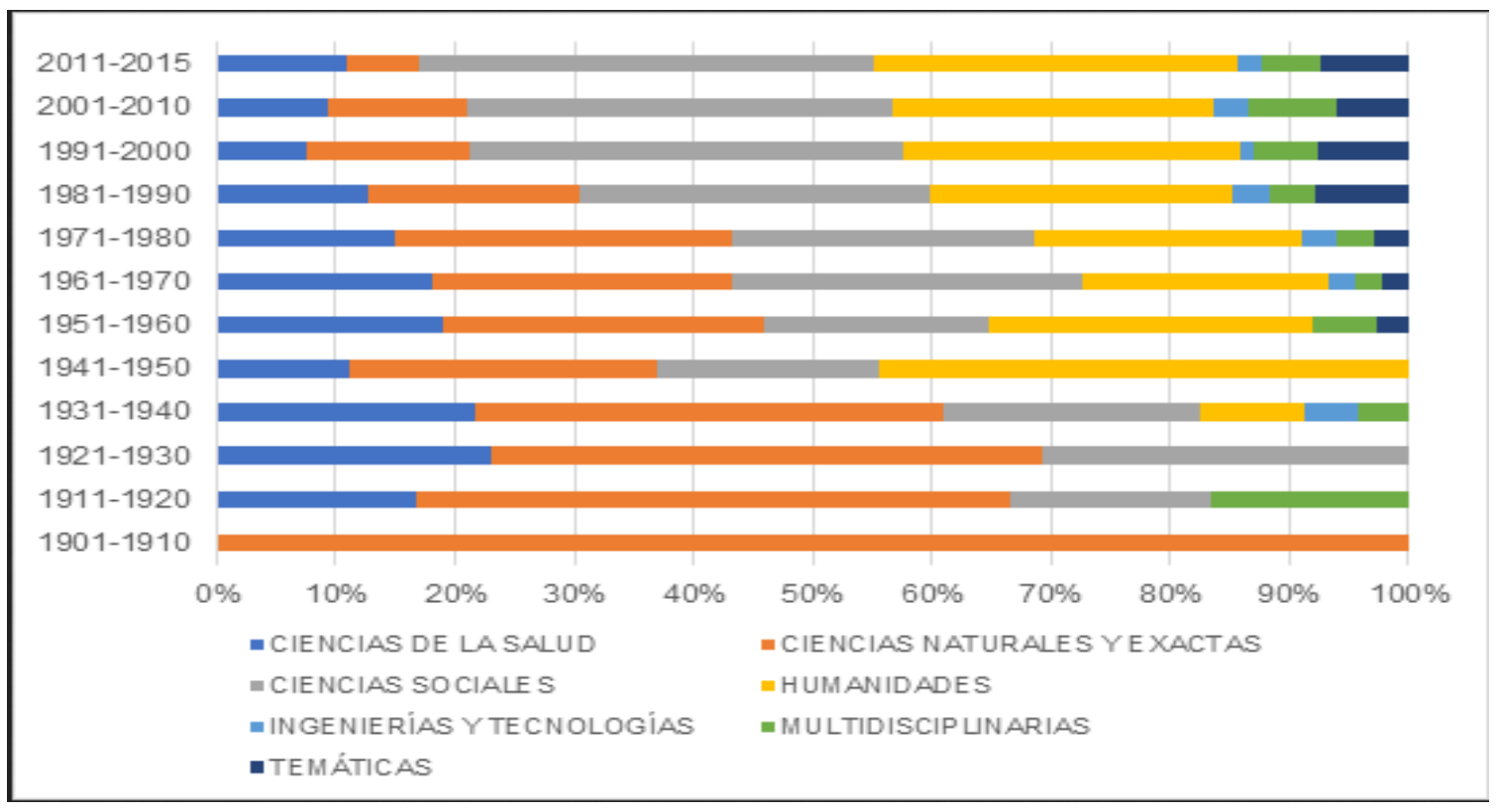

Fuente: elaborada por el autor (n:1208)

En relación al gráfico de la figura 1, las ciencias médicas y de la salud tuvieron una consolidación temprana entre 1838-1950. Más del 50\% de las revistas de estas especialidades surgen entre 1950 y 1970. Las ciencias médicas son especializaciones muy consolidadas dentro del mundo científico donde su legitimidad en el sentido de autoridad científica es precedente al proceso de institucionalización y profesionalización de otras áreas científicas en la región. En la misma línea se encuentran las ciencias naturales y exactas con la mayor proporción de revistas editada en esas disciplinas antes de 1980 (más del 40\% del total).

Un caso interesante es del de las ciencias agrarias. En el contexto de constitución del espacio latinoamericano de revistas científicas, hemos advertido que buena parte de las políticas de diagnóstico y evaluación de la ciencia publicada en revistas tuvo como eje articulador la búsqueda por conocer la cuestión agraria por parte del departamento de agricultura de EEUU y de la OEA. Es decir, fueron dichas organizaciones quienes motorizaron las investigaciones de recopilación y búsqueda de revistas asociadas a temas agrarias (Salatino, 2018a). El período histórico de estos desarrollos (1946-1969) nos indica la necesidad por parte de estas organizaciones de conocer los debates académicos referidos a la problemática de la tierra, las disputas por la tenencia de tierras y las numerosas apuestas por llevar adelante procesos de reforma agraria en muchos países de la región. Este interés además tuvo ligazón con una primigenia y sostenida presencia de estudios agrarios y su consecuente consolidación en proyectos editoriales. Las ciencias agrarias por sus objetos de investigación poseen una orientación local y regional muy importante por lo que se propició su circulación nacional y latinoamericana.

Por su parte, las humanidades tendrán una expansión importante entre 1940 y 1970. La institucionalización de la filosofía particularmente tuvo una etapa muy temprana que se vio consolidada en parte en la generación de un dinámico circuito nacional orientado por importantes revistas científicas. 
Podemos mencionar los Anales de Filología Clásica o los Cuadernos de Filosofía que aún se editan y han permitido la estructuración de un diálogo fecundo desde la década de 1940. Ya a partir de la década de 1970 y 1980, son las revistas de ciencias sociales las que inician un cambio morfológico muy importante en el espacio argentino. Es decir, aquella estructuración orientada por revistas de las ciencias médicas, exactas y naturales comienza crecientemente a ser transformado por la incorporación al espacio de un gran número de revistas de ciencias sociales. $\mathrm{Al}$ año 2016/2017, las ciencias sociales y las humanidades representan el $60 \%$ del total de revistas editadas en Argentina, mientras que las ciencias naturales, exactas y médicas el 26.3\%.

Como se puede observar en la figura 1 , la composición relativa de los períodos correspondientes a la década de 1980, 1990 y las primeras del siglo XXI demuestran una exigua participación de las áreas exactas, médicas y naturales en comparación con el crecimiento de las revistas de humanidades y las ciencias sociales. Sin embargo, en términos absolutos el número de revistas de las áreas exactas, médicas y naturales crece, aunque no con el ritmo de crecimiento de las ciencias sociales.

El cambio morfológico del espacio argentino relativo a la composición disciplinar nos indica considerar el grado de internacionalización de las ciencias médicas, naturales y exactas y las estrategias de publicación que de ellas se desprende. Particularmente, nos invita a considerar las diferencias en las prácticas de publicación entre las ciencias físico-naturales y las sociales. Mientras que los/as agentes de las ciencias sociales pueden orientar casi completamente sus trabajos a espacios nacionales o regionales en español, en las ciencias exactas y naturales ese tipo de publicación es mucho más restringido, pueden redondear un perfil, pero no suplantar la publicación internacional en inglés. En especial porque las lógicas de consagración y acumulación de capital científico en estas áreas han girado hacia una perspectiva estrictamente de corriente principal.

Avanzando en las características morfológicas del espacio argentino de revistas científicas, ahora nos centramos en la visibilidad, el acceso y la indexación. Para el caso de las revistas argentinas, contamos con estudios que han analizado la cuestión del acceso abierto y la visibilidad en función de algunas disciplinas específicas (Colombo, 2009; Romanos de Tiratel, Giunti y Parada, 2003, Romanos de Tiratel y López, 2004; Romanos de Tiratel y Giunti, 2005). Y en otros casos donde se ha problematizado la cuestión del acceso abierto y sus consecuencias en la circulación de las revistas nacionales (Martinovich, 2019; Beigel y Salatino, 2015).

Para este trabajo hemos agregado en una sola variable las diversas formas de publicación en formato digital, ya sea en una plataforma o software completamente digital del tipo Open Journal Systems (OJS) o la publicación en formato HTML o PDF. Identificamos, por tanto, revistas editadas solamente en papel, en papel y algún formato digital y solamente en digital. Encontramos que más del $50 \%$ de las revistas argentinas se editan únicamente en formato papel. Éste es un rasgo fundamental a la hora de pensar la circulación nacional de revistas. Ya bien adentrados en el siglo XXI, aún se continúa editando en papel cuando desde los especialistas en bibliotecología hasta buena parte de la comunidad científica se recomiendan formatos digitales. El formato papel trae consigo un alto costo en el proceso editorial y en el de distribución, implica además la práctica de suscripción a partir de la cual se financia parte de la publicación y restringe espacialmente la circulación de sus contenidos. Una revista papel solo será leída, comentada y tal vez citada si se puede acceder a ella a través de la distribución de la Facultad o instituto o mediante su acceso físico en bibliotecas, algo que será siempre menor al alcance que tienen las revistas en texto completo disponible en acceso abierto. Durante la década de los noventa las suscripciones en bibliotecas eran más corrientes y fue usual la existencia de grandes hemerotecas en las universidades nacionales que incluso divulgaban las novedades. Actualmente, dado el grado de digitalización y la falta de recursos, las hemerotecas ya no suscriben tanto como antes por lo que el acceso a revistas editadas en papel se restringe aún más.

La preponderancia de la edición en papel es extendida en todas las áreas, siendo las ciencias de la salud, naturales y exactas las que poseen una mayor proporción sobre el total de revistas. Esto limita ampliamente las posibilidades de una revista de ser leída, comentada, citada y, por tanto, conocida dentro del campo científico. 
En contraposición, las ciencias sociales y humanidades son las áreas con mayor proporción de edición en algún formato digital.

La incidencia concreta del soporte de edición atañe a las posibilidades de acceder a los contenidos publicados. Con el actual desarrollo de las TICs y la extensión de internet en buena parte del territorio nacional si una revista se edita en algún formato digital es factible de ser encontrada, leída, descargada y utilizada por cualquier persona sea o no con fines académicos. Incluso, una publicación editada en formato digital no garantiza per se que sea accesible a texto completo. Una revista puede estar editada completamente en una plataforma de gestión editorial de última generación, pero sus contenidos pueden ser sólo accesibles vía suscripción. Aquí posiblemente podremos conocer títulos y autores/as de los artículos, pero deberíamos contar con una suscripción institucional o individual para leer, descargar y utilizarlos.

Separándonos del análisis del soporte en sí, cabe preguntarnos, dado el desarrollo de la digitalización, por qué aún continúan editándose revistas en soporte papel. $\mathrm{Al}$ respecto, en la última sección de este trabajo ensayamos una hipótesis asociada a la generación de redes locales cimentado por una tradición conservadora de la edición.

Otro dato relevante para analizar el universo de revistas argentinas es la cantidad de publicaciones sin indexación. Aquí se pone en juego un aspecto de las revistas científicas vinculado a su (e)valuación según las reglas editoriales vigentes en bases de datos y, al mismo tiempo, la restricción de su consideración en los sistemas de evaluación de investigadores y/o instituciones. En función del primer aspecto, una revista que no se encuentra indexada se asume como de mala calidad, tanto editorialmente como de contenido, muy en sintonía con las posturas que asumen la indexación como garante de excelencia cientifica. En este sentido, podemos en primera instancia señalar que "el mundo indexado" no es monolítico y homogéneo y que, por lo tanto, la inclusión de una revista en Scopus, SciELO, Catálogo de Latindex o Web of Science implica diferentes instancias simbólicas y materiales (Salatino, 2018a, 2018b). Y, en segundo lugar, la indexación como sinónimo de "buena ciencia" invisibiliza una estructura que engloba diferentes fenómenos, vincula patrones cuantitativos de evaluación de la ciencia y clasifica de manera jerárquica artículos y revistas científicas. La indexación pasa de ser un "índice", un "indicador" y, en definitiva, de proveer un indicio sobre la calidad eventual de la producción científica, a constituirse en un ícono, valorado en sí mismo, que acaba sustituyendo al objeto que pretende representar. En otras palabras, se convierte en un fetiche, pasa a tener una valía propia y, de ser una señal de que un trabajo científico concluido pueda ser de relevancia y calidad, pasa a convertirse en el objetivo primero y previo del mismo: el conseguir ser publicado en una revista bien indexada (Salatino y López-Ruíz, 2019).

Concretamente dentro del mundo editorial la consideración de la calidad de los contenidos se vincula con la evaluación por revisores ciegos o alguna otra forma de evaluar los artículos. En términos generales, la revisión por pares es requisito para pedir indexación. Sin embargo, no podemos afirmar a priori que todas las revistas que no están indexadas no poseen revisión o son simplemente de "mala" calidad. En función de la relación indexación y regímenes de evaluación, las revistas no indexadas generalmente no otorgan los réditos simbólicos necesarios para la competencia científica internacional y, por tanto, son aisladas de los sistemas de evaluación de investigadores y/o instituciones lo que restringe su circulación. Incluso podemos señalar que la indexación representa una forma de extensión de la visibilidad de las revistas simplemente con el hecho de incluir en su sitio web a la publicación en cuestión.

El 34,4\% del total de revistas argentinas no poseen ninguna indexación. Este es un dato muy importante ya que nos interroga acerca de los motivos por los cuales aún existen estas revistas, muchas de ellas editadas desde principios del siglo XIX. La distribución de este grupo de revistas no indexadas según su año de creación nos indica una larga tradición de publicación, casi el 50\% de revistas de este grupo fueron creadas antes del año 2000 y son en su mayoría revistas de ciencias médicas, naturales y exactas editadas por organizaciones de la sociedad civil (academias, asociaciones profesionales y consejos profesionales). Por lo que representan un circuito tradicional, orientado por el vínculo vía membresía, por la participación de los autores en actividades 
oficiales de las organizaciones (del estilo encuentros, congresos y jornadas), y en general estas publicaciones tienen el formato de anales, boletines o papeles de trabajo. Del grupo de revistas no indexadas que son de más reciente creación, la mayoría son publicaciones pertenecientes a las ciencias sociales y humanidades, editadas en formato digital por lo que es probable que aspiran o se encuentran en la búsqueda de ser incluidas en alguna base de datos.

Las revistas indexadas representan el 65,6\% del total, ya sea en el Catálogo de Latindex (677), DOAJ (169), SciELO (127), RedALyC (70), Scopus (62) o Web of Science (15). Un fenómeno importante a considerar refiere a la implementación de una nueva versión del Catálogo de Latindex denominado Catálogo 2.0. Desde el año 2018 y concretamente a partir de enero de 2019, se inició un proceso de evaluación nuevo en el cual los criterios de inclusión se enfocan estrictamente en las publicaciones electrónicas. Esto llevó a que el Catálogo tradicional forme parte de un recurso llamado Catálogo histórico y se inicie una nueva época a partir de 2019 en la cual al momento cuenta con 1087 revistas (octubre de 2019). Para el caso argentino el proceso de selección se encuentra demorado y sólo 97 revistas se encuentran incluidas. En términos estadísticos, si excluimos las revistas indexadas en la colección nacional del Catálogo de Latindex, el 65,5\% de revistas indexadas se reduciría al $45,6 \%$ del total de revistas dado el peso preponderante que posee Latindex a nivel regional y nacional.

En la figura 2 se encuentran representadas las revistas indexadas y clasificadas según el espacio de circulación: regional si está indexada en Latindex Catálogo, SciELO y/o RedALyC; corriente principal si está incluida en Web of Science y/o Scopus y; transnacional en acceso abierto si las revistas se encuentran en DOAJ y/o Dialnet.

FIGURA 2

Revistas argentinas indexadas según su inclusión en bases de datos, $\mathrm{n}=793$

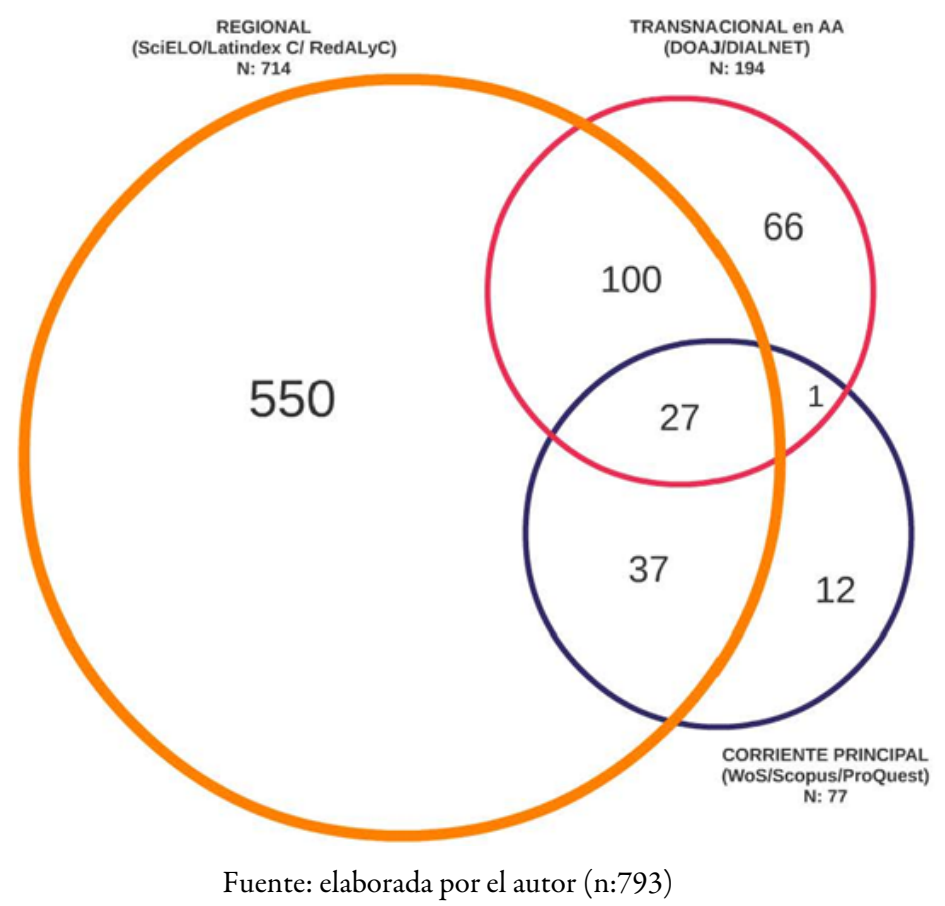

En la figura anterior podemos observar la preponderancia de las bases regionales en la circulación de revistas argentinas; 714 revistas se encuentran incluidas en SciELO, RedALyC y/o Latindex Catálogo. Asimismo, la representación argentina en bases de corriente principal es bastante baja en relación al total de revistas indexadas (9,7\%). Por tanto, el perfil de las publicaciones científicas argentinas tiene principalmente anclajes nacionales y regionales de circulación. 
Es importante destacar aquí un grupo de revistas que poseen múltiples inclusiones y que, por tanto, han diversificado sus estrategias de visibilidad y acceso. En primer lugar, se trata de revistas que han desarrollado un fuerte proceso de profesionalización dada la necesidad de contar con equipos y conocimientos técnicos necesarios para iniciar los procesos de indexación. Es decir, para ser indexada una revista no simplemente se debe chequear criterios específicos, sino que esto trae consigo la necesidad de contar con una adecuación diaria y cotidiana a prácticas orientadas por esos criterios.

La distribución de la inclusión de revistas según circuito de publicación y área disciplinar nos muestra un interesante paneo de la diversidad presentes en el mundo de la publicación indexada. Las ciencias médicas, naturales y exactas cuentan con el porcentaje más alto de todas las áreas disciplinares en la corriente principal. Más del 60\% sólo se encuentran indexadas en Web of Science o Scopus. En contraposición, las ciencias sociales y las humanidades son las áreas con mayor representación en bases regionales de revistas. Además, representan una amplia inclusión en todos los circuitos, lo que indica una búsqueda direccionada hacia generar amplios espacios de visibilidad y acceso.

\section{MAPEO ESPACIO-INSTITUCIONAL DE LAS REVISTAS UNIVERSITARIAS ARGENTINAS}

Los estudios disponibles coinciden en señalar que el espacio regional de revistas es eminentemente público (Alperin, Babini y Fischman, 2014; Babini, 2016; Bongiovani, 2015; Miguel, Bongiovani, Gómez y Bueno-de-la-Fuente, 2013), es decir, son los estados nacionales a través de sus políticas públicas y correspondientes organismos científicos quienes financian la edición de revistas. Los proyectos de investigación que derivan en publicaciones, las becas de posgrado e investigación, los programas de posgraduación, los salarios de los agentes científicos-universitarios, la infraestructura en la cual las revistas llevan adelante sus actividades, los árbitros que evalúan artículos, todos estos elementos, son financiados directa o indirectamente por el estado nacional en el caso argentino. Este rasgo estructural es fuertemente contrastante con la realidad editorial en Europa y EE.UU. donde existen muchas editoriales científicas comerciales.

En nuestra aproximación, las instituciones editoras ${ }^{3}$, principalmente universidades y organismos no gubernamentales forman parte de la infraestructura de comunicación científica lo que implica en primera instancia un reconocimiento de dinámicas estatales asociadas a los campos científicos nacionales. La articulación entre las políticas públicas estatales asociadas a la producción y circulación de conocimiento científico incumbe indefectiblemente a las formas e instrumentos en que ese conocimiento circula. Por tanto, las revistas científicas como espacio de articulación entre editores, árbitros, comités científicos, usuarios, bases de datos e indexadores se encuentran ancladas institucionalmente por lo que su capital editorial es situado local/nacionalmente. El campo científico-universitario argentino se encuentra atravesado por culturas evaluativas que privilegian la publicación científica y, por tanto, esto redunda en la creación de proyectos editoriales.

Mencionamos en el primer apartado que éste es un fenómeno presente en América Latina en la década de 1990 que responde a los cambios en las reglas del juego de la competencia científica internacional. Paulatinamente se propició la valoración de la productividad científica, la indexación como garante de excelencia y un conjunto de criterios cuantitativos de evaluación de la ciencia que privilegió la publicación mainstream como guía simbólica y material en los campos científicos latinoamericanos. Así fue como en los noventa hubo una explosión de revistas científicas en toda la región y, concretamente, en Argentina debido a la necesidad de generar espacios de publicación en español (o portugués). Es decir, se buscó generar revistas locales que permitan a investigadores/as publicar sin tener que mediar con los desafíos lingüísticos de la publicación en inglés. Esto se profundizó al tiempo que las culturas evaluativas nacionales generaron recompensas materiales y simbólicas a la publicación científica (PROINCE, concursos docentes 
y CONICET). En el caso del PROINCE por su valorización de la revista argentina sin pretensiones de indexación ${ }^{4}$ y el CONICET por su apertura a recompensar la revista latinoamericana indexada en repositorios regionales como Latindex, SciELO, RedALyC y nacionales como el Núcleo Básico de Revistas.

Concentrémonos ahora en el sub-universo de revistas argentinas editadas en las universidades nacionales que fueron responsables principales de la proliferación de revistas en las últimas décadas. Del total de revistas argentinas, el $41 \%$ está editado por alguna universidad nacional lo que implica un proceso de fuerte concentración de la edición. Tal es el caso de la Universidad de Buenos Aires (92), la Universidad Nacional de La Plata (63), Universidad Nacional de Rosario (41), Universidad Nacional de Cuyo (38), Universidad Nacional de Córdoba (35), Universidad Nacional de Tucumán (24), Pontificia Universidad Católica Santa María de los Buenos Aires (22), Universidad Nacional de Mar del Plata (19), Universidad Nacional del Nordeste (15), Universidad Nacional del Litoral (14), Universidad Nacional de Río Cuarto (14), Universidad Nacional de San Luis (12), Universidad de Palermo (12), Universidad Nacional de La Pampa (12), Universidad Nacional del Centro de la Provincia de Buenos Aires (10) y Universidad Nacional del Comahue (10). El rol central de la UBA y la UNLP, posicionan a CABA y la provincia de Buenos Aires como el centro de edición de revistas, seguidas por provincias del centro nacional como Córdoba y Santa Fe.

A continuación, desagregaremos las marchas y contramarchas de las revistas científicas dado el contexto de la edición universitaria y las culturas evaluativas. Si consideramos las fechas de creación de revistas, las universidades nacionales se erigieron en las principales instituciones editoras a partir de la década de 1990. Anteriormente, el predominio correspondía a ONGs, especialmente asociaciones científicas y academias profesionales como observamos anteriormente. La expansión de creación de revistas en el seno de universidades nacionales es concomitante con la instauración cada vez más progresiva valoración del artículo como objeto privilegiado de publicación. El período de regionalización e internacionalización del espacio latinoamericano de revistas argentinas tuvo por tanto a las universidades nacionales como su principal motor.

Podemos advertir un doble fenómeno al momento de pensar este proceso: en primer lugar, la configuración de una estrategia de circulación regional, potenciada por revistas editadas en español, direccionada por determinadas disciplinas y con un afincamiento local importante. Y, en segundo término, el desarrollo de una estructura heterogénea basada en diversas capacidades científicas e institucionales de los "hacedores" de la comunicación científica. Esto provocó un proceso de diferenciación vinculado a las formas de edición, visibilización, acceso y circulación de las revistas que produjo diferentes segmentaciones hacia el interior del circuito nacional.

Si nos adentramos en la publicación universitaria de revistas concretamente, detectamos que las ciencias sociales y las humanidades representan el $74 \%$-preponderancia de disciplinas como historia, educación, economía y filosofía-, y en un segundo lugar las ciencias naturales y exactas con un lejano 13\% de revistas editadas -principalmente de ciencias agrarias, medicina y biología- (figura 3). 
FIGURA 3

Revistas universitarias argentinas según área disciplinar de adscripción

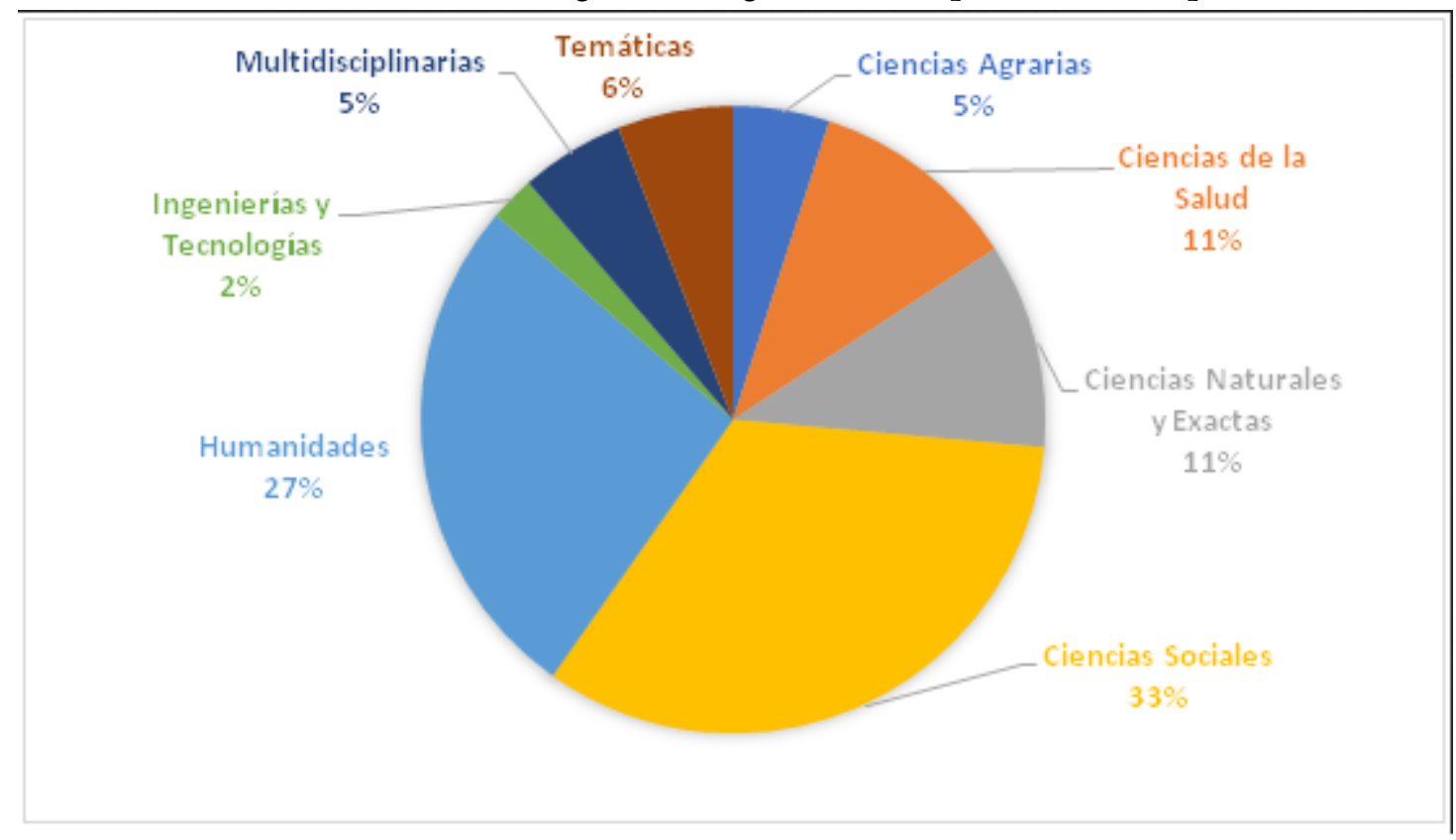

Fuente: elaborada por el autor (n:500)

La circulación de las revistas se encuentra fuertemente vinculada al tipo de soporte (papel y/o digital), la disponibilidad en texto completo, su inclusión en bases de acceso abierto y su indexación. Todos estos elementos geolocalizan el tipo de circulación y por tanto la visibilidad de las producciones allí publicadas. Es así como las universidades tradicionales, con mayor matrícula estudiantil, con planteles docentes numerosas y localizadas en los nodos metropolitanos centrales poseen una mayor capacidad institucional para publicar y orientar la circulación de sus revistas.

\section{LAS REVISTAS UNIVERSITARIAS EN LA BISAGRA DE LA CIRCULACIÓN LOCAL Y MULTIESCALAR}

Otro dato relevante hasta aquí refiere a la espacialidad de la circulación y la escala en la que se mueven las revistas argentinas. Es curioso que dado el grado de desarrollo de la competencia científica internacional y la expansión de la edición en formatos digitales exista un grupo importante de revistas no indexadas incluso y especialmente en grandes universidades como La Plata y UBA. En estudios recientes, donde se han analizado espacios de publicación alternativos (Chavarro, Tang, y Rfols, 2014, 2017; Miguel, González y ChinchillaRodríguez, 2015; Ramos Zincke, 2014; Salager-Meyer, 2014) y especialmente situados en una perspectiva de los/as agentes científicos, han destacado que más allá de la proliferación de incentivos para publicar internacionalmente, en regiones periféricas aún persiste un tipo de publicación no mainstream.

Para el caso de las revistas argentinas, podemos afirmar el desarrollo de un fenómeno que refleja por lo menos dos tendencias hacia el interior del espacio de publicaciones periódicas argentino, por un lado, la resistencia de espacios estrictamente locales e institucionales de publicación que por fuera de las reglas de la competencia científica internacional ha desarrollado espacios de comunicación de larga tradición y muy consolidadas en las fronteras de sus instituciones editoras y, por otra parte, la proliferación de proyectos editoriales que nacen situados o localizados en respuesta precisamente a la creciente presión por la publicación, al parecer como traducción del publish or perish. Frente a esta primera tendencia, nos podemos preguntar ¿por qué existen tantas revistas con circulación restringida? Una primera aproximación nos sugiere que muchos de los proyectos más locales de revistas son parte de la estrategia de un agente o grupo de estudio/ 
investigación que han buscado mediante un proyecto editorial, por un lado, una vía de publicación de sus propias producciones, y por otro, el inicio de un posicionamiento hacia el interior de sus campos disciplinares, facultades e incluso universidades. Para la segunda tendencia interesa observar la estrategia de indexación que para muchos proyectos editoriales marca espacios de visibilidad y acceso. Que una revista ingrese en la colección de SciELO Argentina implica un efecto para su valorización en los procesos de evaluación, pero también de visibilidad y acceso ya que toda la producción de dicha revista se encuentra en un sitio tecnológicamente avanzado y funcional que permite descargas a texto completo.

Un elemento central en la constitución de circuitos locales de circulación es la cuestión de la lengua de la publicación. América Latina, donde la mayoría de la población posee como lengua nativa el español o el portugués, es una región dominada frente a los centros mundiales de lengua (Swaan, 2001; Heilbron, 2014). Por tanto, un/a investigador/a argentino/a tiene que desarrollar una acumulación temprana de capital cultural y lingüístico que le permita iniciar un patrón de publicación en inglés, y al mismo tiempo, lo/a oriente hacia una carrera más internacionalizada vía movilidades académicas, participación en proyectos, colaboraciones, becas, entre otros. El proceso de regionalización explicado en el comienzo de este trabajo responde en parte a estas mismas cuestiones: la estrategia por generar espacios de producción, publicación y comunicación del conocimiento latinoamericano que permita niveles de visibilidad, acceso e impacto que logren ser una alternativa a la constitución y consolidación mundial de la corriente principal en general, y la supremacía del inglés en particular. El español dentro del mundo de la ciencia es periférico e incluso en Brasil a pesar de la cercanía regional. Por tanto, el hecho de que las revistas argentinas se publiquen en español implica ceñir las fronteras de circulación a espacios nacionales en el cual más allá de la tan remanida globalización de la ciencia, en el siglo XXI existan circulaciones locales en contextos globales.

Del universo de revistas universitarias argentinas solo cuatro se editan completamente en inglés: The Journal of Management and Economics (UBA), Journal of computer science and technology (UNLP), Iberoamerican journal of project management (UNMP) y Latin American Applied Research (UNSur). La apuesta aquí es a por lo menos ser leídas (tal vez citadas) en espacios de circulación en inglés que les permitan a estas revistas generar audiencias internacionales no latinoamericanas. En relación al idioma de aceptación de artículos, el 86,2\% de las revistas sólo permiten producciones en español. Este dato nos marca fuertemente los límites lingüísticos de circulación de las revistas científicas ya que sólo buscarán audiencias en español (tal vez en portugués) pero claramente no en inglés. Y en su anverso, quienes publican allí sólo deben escribir en español (o esperar ser traducidos) lo que dificultan aún más la circulación en otros espacios no hispanohablantes. Este rasgo lingüístico nos marca un claro perfil de la circulación de las revistas argentinas que en su gran mayoría están indexadas en repositorios latinoamericanos y cuya máxima aspiración será la circulación regional.

Si nos abocamos ahora a las revistas que no están indexadas y/o se publican solo en papel, la emergencia de espacios locales de circulación de revistas puede ser entendido a partir de la búsqueda de reconocimiento y legitimación en dos niveles, uno de ellos ligado concretamente a la constitución de un espacio editorial guiado por la búsqueda de acumular lo que denominamos capital editorial -orientado hacia el interior de las instituciones editoras- y otro, vinculado a un capital más propiamente científico que busca consagración según las reglas de la competencia científica nacional -en el caso argentino, orientado por la cultura evaluativa más flexible a este tipo de publicaciones como es el PROINCE o los concursos docentes en universidades nacionales.

El capital editorial tiene fuertes imbricaciones con la lógica del capital social, es decir, la puesta en marcha de un conjunto de estrategias para la consecución de un proceso de distinción/reconocimiento/consagración dentro de un espacio editorial asociado directamente con la legitimación de redes de pares. En este sentido, considerar las relaciones sociales y personales como parte de un capital social aplicado a un proyecto editorial no tan sólo implica la necesaria generación de una red de relaciones sino una definición de territorialidad. Bourdieu (1986) afirma que "la definición del volumen total de capital social poseído por un agente depende 
de la red de conexiones que puede movilizar afectivamente y en el volumen del capital que posee en sí (económico, cultural o simbólico)" (Bourdieu, 1986, p.51). Por tanto, la empresa por la cual determinadas revistas como agentes editoriales buscan capital social en el campo académico se define a partir del desarrollo e institucionalización editorial de dichas redes.

El capital social posee un anclaje territorial localizado atravesado por las políticas de digitalización del espacio editorial. Los alcances de la territorialidad de las redes no es exclusivamente una referencia a lo local o a lo global sino a ambas. Y como consecuencia, la extensión de la disputa por el capital social puede poseer un medio digital de legitimación y su recompensa puede estar localmente anclada. La edición universitaria de revistas es un claro ejemplo de la coexistencia y simultaneidad de estrategias de visibilidad y (re)conocimiento científico con fuerte territorialidad local en espacios y circuitos globales de circulación.

Empíricamente hemos operacionalizado la circulación local a partir del cruce de la disponibilidad a texto completo de los contenidos de las revistas, soporte de publicación, indexación y el idioma de publicación. Buscamos así dar cuenta de un fenómeno de circulación que no sólo se reduce a la inclusión o no de una revista en un sistema de indexación sino también considerar la disponibilidad a texto completo de los recursos. Esto implica dar cuenta de formas de circulación orientadas localmente pero que al mismo tiempo no pueden ser consideradas como endogámicas ya que su orientación da cuenta de digitalización y adopción de políticas de acceso abierto. Es una forma de deconstruir sentidos comunes asociados a la calidad de una revista científica a partir de la consideración de su indexación, en este caso, teniendo en cuenta los casos que se encuentran fuera de esas lógicas pero que al mismo tiempo se insertan en redes globales.

FIGURA 4

Revistas universitarias argentinas según disponibilidad a texto completo e indexación

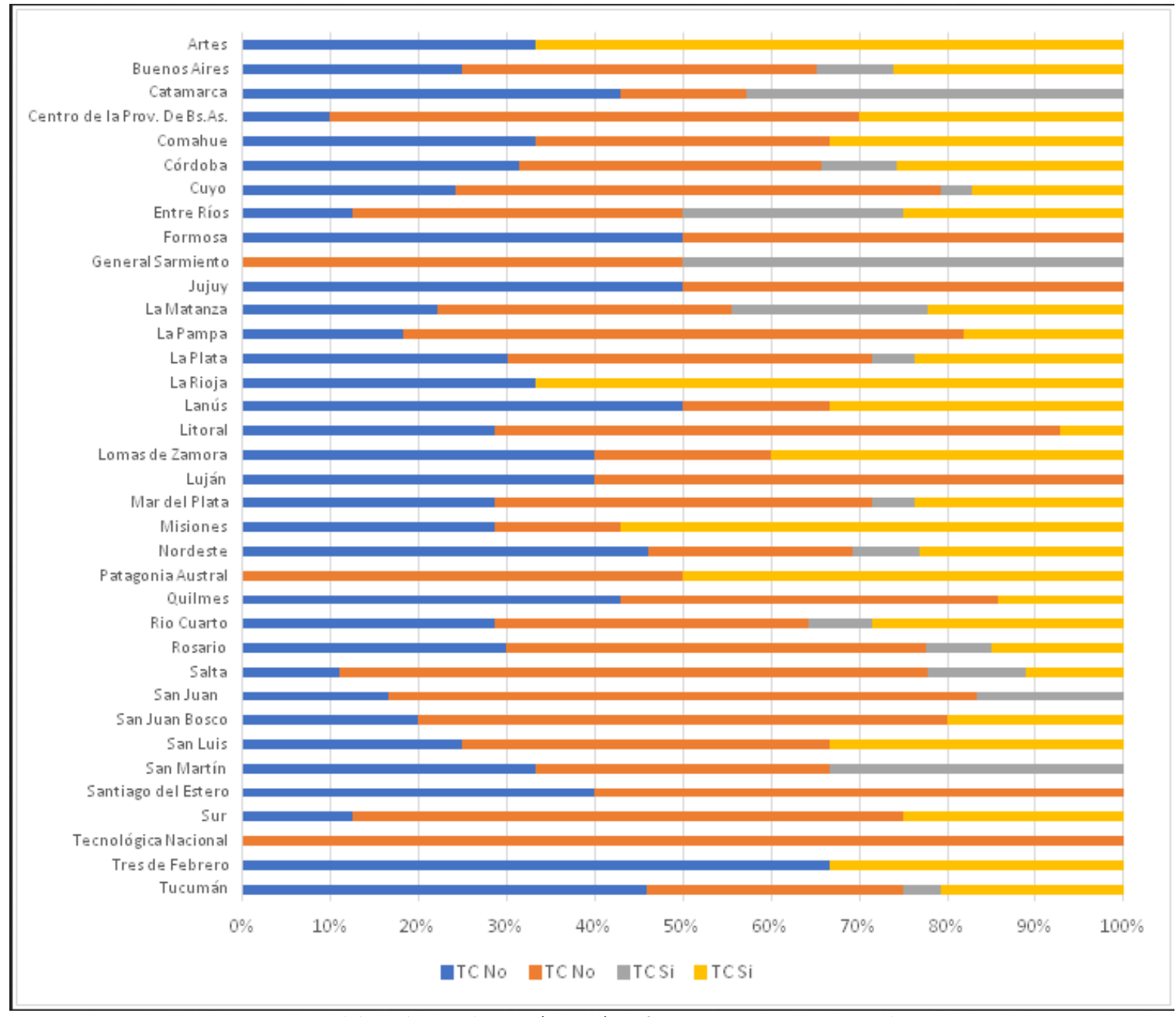

Fuente: Elaborada por el autor (n: 500) Referencias: TC: Texto completo. 
En la figura 4 podemos observar las revistas editadas por universidades nacionales en relación a su inclusión en bases indexadoras y la disponibilidad de sus contenidos en texto completo. La barra azul representa a la proporción de revistas en las cuales su circulación se encuentra ceñida estrictamente a las redes editoriales ya que no han apelado a construir redes de visibilidad y acceso digitales. Es el conjunto de revistas que además de la orientación local podemos advertir si poseen o una estrategia o una deriva editorial artesanal. Entre estas encontramos el caso de la revista Archivos del Movimiento Obrero y la Izquierda editada por un equipo editorial de agentes insertos en el CONICET, la Universidad de Buenos Aires y la Universidad Nacional de San Martín que solo editan en formato papel y no se encuentra disponible en las grandes bases indexadoras. Es una revista que funciona estrictamente vía suscripción y en relación a la consolidación de un grupo/área de estudio específico. Se edita desde 2012, por lo que la decisión de no digitalizar sus contenidos es estrictamente editorial.

Además, la figura 4 nos muestra cuán disímil es la circulación de revistas universitarias, siendo posible trazar perfiles por institución. Son revistas que dependen de condiciones locales dado el estado actual del espacio argentino pero que al mismo tiempo tienden a desarrollar espacios de visibilidad regionales y globales. Cada uno de los casos son diferentes y pueden señalarse singularidades concretas acerca de las explicaciones que ha llevado a cada revista a tener la estrategia editorial que posee en relación a la visibilidad y el acceso. Sin embargo, este fenómeno que hemos sintetizado como bisagra entre lo local y lo global puede ser percibido a partir de la coexistencia de muchas revistas universitarias con largas tradiciones de edición, ancladas localmente por las redes editoriales y con diferentes apuestas de indexación.

El caso de la Universidad de Buenos Aires es relevante. Como mencionamos anteriormente, se trata de la principal editora de revistas de la Argentina con 92 publicaciones periódicas. Si observamos en términos de visibilidad y acceso, el $65 \%$ de las revistas de la UBA no se encuentran a texto completo, de las cuales el $44 \%$ sólo se edita en papel. En relación a la indexación, el $34 \%$ de sus revistas no se encuentran incluidas en una base de datos. Lo interesante aquí es señalar los sitios de indexación del grupo del 66\% sí incluidos: 57 de ellas están en el antiguo Catálogo de Latindex, 7 en SciELO, 6 en RedALyC, 1 en Scopus y ninguna en Web of Science. Esto nos muestra una fuerte orientación regional, especialmente por la preponderancia de Latindex y una casi nula circulación en espacios de corriente principal vía indexación. Principalmente, se destaca una circulación local, intramuros, relacionada a la búsqueda de generar capital social y a la construcción de un proyecto editorial que diferencie a sus agentes de otros en un contexto de necesaria distinción dada la competencia académica hacia el interior de la UBA.

\section{Conclusiones}

La participación latinoamericana en el sistema académico mundial se encuentra sujeta a su rol como periferia y, por tanto, subordinada a las estrategias de consagración de los centros de excelencia. La dinámica establecida entre lo local/nacional/regional/internacional marca de muchas maneras la trayectoria de los agentes e instituciones científicas periféricas. La tensión entre universalismo y endogamia ha sido tema recurrente de la ciencia regional desde su institucionalización. Esa tensión muchas veces llevó a desconocer la estructuración de un sistema de desigualdad científicas entre los Nortes y los Sures que redunda en asimetrías de todo tipo. El proceso mediante el cual unos conocimientos, saberes y prácticas se convierten en referenciales para todo el mundo y, por tanto, universales, es un proceso que tuvo como contrapartida la localización de otros saberes, conocimientos y prácticas como subalternos.

Como hemos observado a partir de la estructuración del espacio de revistas y el proceso histórico de regionalización, las formas de acceso, visibilización, soporte, descargas, indexación, edición y disciplinarización inciden en las formas en las cuales las revistas científicas circulan. Para el caso argentino, hemos constatado una larga tradición editorial (desde por lo menos mediados de siglo XIX) orientada disciplinarmente por las ciencia médicas, naturales y exactas. Será a partir de la década de 1980 que las ciencias sociales y humanidades producirán un cambio morfológico del espacio nacional de revistas. 
Este fenómeno debe ser contextualizado regionalmente en el marco de la expansión de las tecnologías de la comunicación y de la información, la aplicación de políticas de acceso abierto y la emergencia de los grandes portales de revistas (Latindex, SciELO y RedALyC). Incluso debe considerarse la búsqueda de generar espacios de publicación en español (o portugués) que permitiera a investigadores/as latinoamericanos/as acceder a publicar sin enfrentar las limitaciones simbólicas, materiales y lingüísticas que significa publicar en inglés.

El espacio argentino posee rasgos específicos de circulación: es mayoritariamente caracterizado por las ciencias sociales, posee un 34,4\% de revistas sin indexación (porcentaje que aumenta a un 55\% si excluimos al Catálogo de Latindex), el $41 \%$ de las revistas son editadas en una universidad nacional, más del 50\% aún continúa editándose en formato papel y existe un núcleo muy pequeño de revistas que sólo han buscado ser indexadas en Scopus o Web of Science.

En términos analíticos hemos dado cuenta de las particularidades y singularidades de las revistas científicas argentinas. Singularidades en relación a la coexistencia diferentes formas simultáneas y diversas de circulación. Como resultado de este análisis observamos que muchas revistas argentinas apuntan a circular en espacios de visibilidad regionales en español o portugués a partir de su edición digital y su inclusión en bases de acceso abierto como SciELO, Latindex o RedALyC y, además, buscan inclusión en espacios mainstream a través de Web of Science o Scopus. Incluso, un grupo importante de revistas sólo se edita en papel lo que implica una circulación restringida y localmente orientada. En cambio, otras revistas se encuentran en las fronteras de la circulación nacional ya que no se encuentran indexadas, pero poseen una larga tradición de edición, tienen edición digital y se desarrollan en el seno de grandes universidades nacionales. Éste es un fenómeno que sitúa a las revistas universitarias en la bisagra entre lo local dada su territorialidad, lo nacional, regional y global dada las estrategias de visibilidad vía formatos digitales y del idioma de publicación.

En este marco, las revistas científicas han sido clasificadas por los agentes por lo general según su alcance y cobertura. La inclusión en una base de corriente principal indicaría, según las clasificaciones más extendidas, que dicha revista circula internacionalmente, pero eso ela hace internacional? Como contrapartida, las revistas sin indexación son consideradas locales por los gestores de la ciencia, pero para nosotros habría que distinguir fenómenos distintos. ¿Son locales aquellas revistas que desarrollan una agenda local de discusión o aquellas que tienen una circulación restringida, limitada a circuitos que no se alejan prácticamente de la institución editora? Si el caso es el segundo, entonces una revista sin indexación, pero en formato digital podría tener una gran difusión, razón por la cual la indexación no puede ser el criterio único ni primordial para determinar la escala de la circulación de las revistas.

Una consideración importante merece las agendas temáticas y su relación con las escalas de la circulación. Es decir, podríamos afirmar que hay temáticas y problemas local/intra-nacionalmente orientados que circulan en función de las necesidades de contextos de producción específicos. En este sentido, Chavarro, Tang y Ráfols (2017) señalan que existen motivaciones para que investigadores colombianos no publiquen en revistas "mainstream". Cuestiones que tienen que ver con: el entrenamiento en la publicación científica; la necesidad de generar puentes entre discusiones internacionales y locales y; el tratamiento de temas no abordados en revistas de corriente principal. Para el caso argentino podríamos preguntarnos si podemos hacer una analogía con el caso colombiano lo que nos invitaría a avanzar hacia la dimensión de análisis de artículos y sus agendas temáticas. 
En este trabajo, especialmente, nos abocamos especialmente a estudiar un fenómeno singular de circulación local de conocimiento científico. Singular en tanto responde a la identificación de proyectos editoriales de larga data, tradicionalmente anclados a determinadas disciplinas y que continúan publicando en un contexto de creciente orientación internacionalista. Nos aproximamos al estudiar empíricamente este fenómeno a partir del cruce entre la indexación (regional, internacional mainstream o internacional en acceso abierto), el soporte de publicación (formatos digitales desde el HTML hasta gestores editoriales del tipo OJS o formatos clásicos de edición en papel), la disponibilidad a texto completo y el idioma de publicación (mayoritariamente sólo en español para este caso nacional). Estas características nos permiten comprender la existencia de circuitos locales, que en muchos casos se encuentran presentes en las grandes universidades nacionales, que poseen una tradición de publicación más allá de las reglas de la competencia científica internacional o la institucionalización de regímenes de evaluación orientados por criterios cuantitativos.

En el contexto del sistema académico mundial, el espacio argentino de circulación de revistas científicas nos muestra cuan diversa puede ser las formas en que la ciencia se comunica. Cuan equivocados podemos estar a condenar como endogámicas o de mala calidad a la producción publicada en espacios locales. Especialmente, porque como hemos dado cuenta en este trabajo, los circuitos locales se nutren de condiciones estructurales, estrategias de consagración nacionales y se encuentran tensionados por las culturas evaluativas. Y, por tanto, difícilmente podemos reducir los análisis de la ciencia argentina a lo publicado/referenciado en bases de datos, ya sean regionales o internacionales de corriente principal. Reconocemos la necesidad de profundizar el estudio de circuitos locales, en especial, empíricamente para avanzar con la deconstrucción de sentidos comunes que suelen orientar políticas científicas públicas de gestión y evaluación de la ciencia nacional.

\section{REFERENCIAS BIBLIOGRÁFICAS}

Aguado-López, E., y Becerril-García, A. (2016). ¿Publicar o perecer? El caso de las Ciencias Sociales y las Humanidades en Latinoamérica. Revista española de documentación cientifica, 39(4), 1-14. https://doi.org/10.3989/redc.201 6.4 .1356

Alperin, J.P., Nieves, C. M., Schimanski, L. A., Fischman, G. E., Niles, M. T., y McKiernan, E. C. (2019). How significant are the public dimensions of faculty work in review, promotion and tenure documents? ELife, 8, 1-23. https://doi.org/10.7554/eLife.42254

Alperin, J.P., Babini, D., y Fischman, G. (2014). Indicadores de acceso abierto y comunicaciones académicas en América Latina. Buenos Aires: CLACSO/UNESCO. Recuperado de http://biblioteca.clacso.edu.ar/clacso/se /20141217052547/Indicadores_de_acceso_abierto.pdf

Alperin, J.P., Fischman, G., y Willinsky, J. (2008). Open access and scholarly publishing in Latin America: ten flavours and a few reflections. Liinc Em Revista, 1(1), 172-185. https://doi.org/10.18617/liinc.v4i2.269

Ansaldi, W. (1991). La búsqueda de América Latina. Entre el ansia de encontrarla y el temor de no reconocerla. Buenos Aires: Cuadernos de la Universidad de Buenos Aires.

Babini, D. (2016). ¿Derecho o mercancía? El conocimiento como bien común. Megafón. La Batalla de Las Ideas, 8. Recuperado de https://www.clacso.org.ar/megafon/megafon8_articulo2.php

Babini, D., y Machin-mastromatteo, J. D. (2015). Latin American science is meant to be open access: Initiatives and current challenges. Information Development, 31(5), 477-481. https://doi.org/10.1177/0266666915601420

Beigel, F. (2010). La institucionalización de las ciencias sociales en América Latina: entre la autonomía y la dependencia académica. En Autonomia y dependencia académica. Universidad e investigación científica en un circuito periférico: Chile y Argentina (1950-1980) (pp. 47-64). Buenos Aires: Biblos. 
Beigel, F. (2013). The politics of academic autonomy in Latin America. En F. Beigel (Ed.) The Politics of Academic Autonomy in Latin America (pp.1-27). London: Ashgate.

Beigel, F. (2014). Publishing from the periphery: Structural heterogeneity and segmented circuits. The evaluation of scientific publications for tenure in Argentina's CONICET. Current Sociology, 62(5), 743-765. https://doi.or $\mathrm{g} / 10.1177 / 0011392114533977$

Beigel, F. (2015). Culturas (evaluativas) alteradas. Politica Universitaria (IEC-CONADU), 2, 12-21. Recuperado de https://ri.conicet.gov.ar/handle/11336/43518

Beigel, F., y Salatino, M. (2015). Circuitos segmentados de consagración académica: las revistas de ciencias sociales y humanas en la argentina. Información, Cultura y Sociedad, 32,11-36. http://revistascientificas.filo.uba.ar/index .php/ICS/article/view/1342

Bianco, M., Gras, N., y Sutz, J. (2016). Academic Evaluation: Universal Instrument\#? Tool for Development? Minerva, 54(4), 399-421. https://doi.org/10.1007/s11024-016-9306-9

Bongiovani, P. (2015). Conocimientos y opiniones de los evaluadores de carrera docente investigador respecto de las publicaciones de Acceso Abierto. Ponencia presentada en IV Jornadas de Intercambio y Reflexión acerca de la Investigación en Bibliotecología, 29-30 de octubre de 2015, La Plata, Argentina. Recuperada de http://www.me moria.fahce.unlp.edu.ar/trab_eventos/ev.5298/ev.5298.pdf

Bourdieu, P. (1976). Le champ scientifique. Actes de La Recherche en Sciences Sociales, 2, 88-104. https://doi.org/10 $.3406 /$ arss.1976.3454

Bourdieu, P. (1986). The Forms of Capital. En J. Richardson, Handbook of Theory and Research for the Sociology of Education. Westport, CT: Greenwood. https://doi.org/10.1017/CBO9781107415324.004

Bourdieu, P. (2003). El oficio del cientifico. Ciencia de la ciencia y reflexividad. Barcelona: Anagrama.

Chan, L., Kirsop, B., y Arunachalam, S. (2011). Towards Open and Equitable Access to Research and Knowledge for Development. PLOS Medicine, 8(3), 1-4. https://doi.org/10.1371/journal.pmed.1001016

Chavarro, D., Tang, P., y Rafols, I. (2014). Interdisciplinarity and research on local issues: Evidence from a developing country. Research Evaluation, 23(3), 195-209. https://doi.org/10.1093/reseval/rvu012

Chavarro, D., Tang, P., y Ràfols, I. (2017). Why researchers publish in non-mainstream journals: Training, knowledge bridging, and gap filling. Research Policy, 46(9), 1666-1680. https://doi.org/10.1016/j.respol.2017.08.002

Colombo, F. (2009). Visibilidad de las revistas argentinas de medicina en las bases de datos internacionales. En Información, Cultura y Sociedad. No. 20, 41-62. http://revistascientificas.filo.uba.ar/index.php/ICS/article/v iew/805

De-Filippo, D. (2013). Spanish Scientific Output in Communication Sciences in WOS. The Scientific Journals in SSCI (2007-12). Comunicar, 21(41), 25-34. http://dx.doi.org/10.3916/C41-2013-02

Delgado-Troncoso, J. E., y Fischman, G. E. (2014). The future of Latin American academic journals.En B. Cope y A. Phillips (Eds.) The Future of the Academic Journal (pp. 379-400) https://doi.org/10.1533/9781780634647.379

Guédon, J. (2009). It's a Repository, it's a Depository, it's an Archive...: Open Access, Digital Collections and Value. Arbor, 185(737), 581-595. http://dx.doi.org/10.3989/arbor.2009.i737.315

Hanafi, S. (2011). University systems in the Arab East: Publish globally and perish locally vs publish locally and perish globally. Current Sociology, 59(3), 291-309. https://doi.org/10.1177/0011392111400782

Heilbron, J. (2014). The social sciences as an emerging global field. Current Sociology, 62(5), 685-703. https://doi.or $\mathrm{g} / 10.1177 / 0011392113499739$ 
Leite, D., Pinho, I, Miorando, B, y Caregnato, C. (2018). Publish or perish? Avaliação de redes de pesquisa e colaboração com RNPE. Parcerias Estratégicas, 23(47). Recuperado de http://seer.cgee.org.br/index.php/parce rias_estrategicas/article/viewFile/903/821

Leta, J., Thijs, B., y Glänzel, W. (2013). A macro-level study of science in Brazil: seven years later. Encontros Bibli: Revista Eletrônica de Biblioteconomia e Ciência da Informação, 18(36), 51-66. https://doi.org/10.5007/1518-2 924.2013v18n36p51

Liu, M., Hu, X., Wang, Y., y Shi, D. (2018). Survive or perish: Investigating the life cycle of academic journals from 1950 to 2013 using survival analysis methods. Journal of Informetrics, 12(1), 344-364. https://doi.org/10.101 6/j.joi.2018.02.001

Machado, A. M. N., y Bianchetti, L. (2011). (Des)fetichização do produtivismo acadêmico: desafios para o trabalhadorpesquisador. Revista de Administração Empresas, 51(3). https://doi.org/10.1590/S0034-75902011000300005

Martinovich, V. (2019). Revistas científicas argentinas de acceso abierto y circulación internacional. Un análisis desde la teoría de los campos de Pierre Bourdieu. Información, cultura y sociedad, 40, 93-116. http://dx.doi.org/10.3 4096\%2Fics.i40.5540

McKiernan, E.C., Schimanski, L. A., Muñoz Nieves, C., Matthias, L., Niles, M.T., y Alperin, J.P. (2019). Use of the Journal Impact Factor in academic review, promotion, and tenure evaluations. PeerJ Preprints, 7, e27638v2. ht tps://doi.org/10.7287/peerj.preprints.27638v2

Miguel, S., Bongiovani, P.C., Gómez, N.D., y Bueno-de-la-Fuente, G. (2013) Prospect for Development of Open Access in Argentina. The Journal of Academic Librarianship 39(1), 1-2 .https://doi.org/10.1016/j.acalib.2012. 10.002

Miguel, S., González, C., y Chinchilla-Rodríguez, Z. (2015). Lo local y lo global en la producción científica argentina con visibilidad en Scopus, 2008-2012. Dimensiones nacionales e internacionales de la investigación. Información, Cultura y Sociedad, 32(1), 59-78. http://dx.doi.org/10.34096\%2Fics.i32.1375

Minniti, S., Santoro, V., y Belli, S. (2018). Mapping the development of Open Access in Latin America and Caribbean countries. An analysis of Web of Science Core Collection and SciELO Citation Index (2005-2017). Scientometrics, 117(3), 1905-1930. https://doi.org/10.1007/s11192-018-2950-0

Ramos Zincke, C. (2014). Local and global communications in Chilean social science: Inequality and relative autonomy. Current Sociology, 62(5), 704-722. https://doi.org/10.1177/0011392114521374

Romanos de Tiratel, S. y Giunti, M. G. (2005). Las revistas argentinas de Filosofía: Visibilidad en bases de datos internacionales. Información, Cultura y Sociedad, 13, 57-79. http://revistascientificas.filo.uba.ar/index.php/IC S/article/view/898

Romanos de Tiratel, S., Giunti, M. G. y Parada, A. (2003). Las revistas argentinas de filología, literatura y lingüística: visibilidad en bases de datos internacionales. Ciência da Informação. 32(3), 128-139. http://dx.doi.org/10.159 0/S0100-19652003000300015

Romanos de Tiratel, S., y López, N. (2004). Las revistas argentinas de Historia: visibilidad en bases de datos internacionales. Información, Cultura y Sociedad, 11, 95-115. http://revistascientificas.filo.uba.ar/index.php/I $\mathrm{CS} /$ article/view/915

Rozemblum, C. (2014). El problema de la visibilidad en revistas científicas argentinas de Humanidades y Ciencias Sociales: Estudio de casos en Historia y Filosofía (Tesis de maestría). Universidad Nacional de Quilmes. Recuperado de http://www.memoria.fahce.unlp.edu.ar/tesis/te.1031/te.1031.pdf

Salager-Meyer, F. (2014). Journal of English for Academic Purposes Writing and publishing in peripheral scholarly journals: How to enhance the global influence of multilingual scholars\#? Journal of English for Academic Purposes, 13, 78-82. https://doi.org/10.1016/j.jeap.2013.11.003

Salatino, M. (2018a). La estructura del espacio latinoamericano de revistas cientificas (Tesis de doctorado). Universidad Nacional de Cuyo. Facultad de ciencias políticas y sociales. Recuperado de http://bdigital.uncu.edu.ar/objetos_ digitales/10720/salatino-estructuraespaciolatinoamericano-revistascientficas.pdf 
Salatino, M. (2018b). Más Allá de la Indexación: Circuitos de Publicación de Ciencias Sociales en Argentina y Brasil. Dados, 61(1), 255-287. https://doi.org/10.1590/001152582018152

Salatino, M., y López-Ruiz, O. (2019). El fetichismo de la indexación. Una crítica latinoamericana a los regímenes de evaluación de la ciencia mundial. Revista Iberoamericana de Ciencia, Tecnología y Sociedad. [en evaluación]

Swaan, A. de. (2001). Words of the World. Great Britain: Polity Press.

Velho, L. (1986). The "meaning" of citation in the context of a scientifically peripheral country. Scientometrics, 9(1-2), 71-89. https://doi.org/10.1007/BF02016609

Vessuri, H. (1987). La revista científica periférica. El caso de Acta Científica Venezolana. Interciencia. Recuperado de http://www.ivic.gob.ve/estudio_de_la_ciencia/Enlapublic/documentos/Revicient.pdf

Zuin, A. S., y Bianchetti, L. (2015). O produtivismo na era do "publique, apareça ou pereça": um equilíbrio difícil e necessário. Cadernos de Pesquisa, 45(158), 726-750. https://dx.doi.org/10.1590/198053143294

\section{Notas}

1 Se trata de una base de revistas científicas activas al año 2016 con actualización de las indexaciones al año 2017. Se construyó a partir de las series ISSN de Argentina, la Bibliografía Nacional de Publicaciones Periódicas Argentinas Registradas (BINPAR) y del Directorio de Latindex. Se inició un proceso de filtrado en el cual se consideró el ISSN como guía, sin embargo, encontramos inconsistencias en los listados vinculados con cuestiones propiamente editoriales. Es decir, en la trayectoria editorial de una misma revista se pueden obtener diferentes números de registro ISSN dependiendo especialmente de la creación y finalización de la edición a pesar de que la revista en sí como agente continúa siendo la misma. Por otra parte, una misma revista puede tener un ISSN y un ISSN-L (para el caso de edición en soportes digitales) lo cual complejiza aún más el registro de los datos ya que una revista puede tener una larga tradición de edición en soporte papel y, en determinado momento de su trayectoria, puede optar por el soporte digital por lo cual convive con dos ISSN, pero puede suceder que la edición en formato papel se suspenda y sólo perdure en su versión digital; o incluso lo contrario.

Luego, se incluyeron las revistas argentinas incluidas en las bases indexadoras regionales (Latindex Catálogo, SciELO y RedALyC). A las revistas indexadas en las bases regionales adicionamos las revistas que se encuentran incorporadas a Web of Science en todos sus recursos (Science Citation Index, Social Science Citation Index, Arts and Humanities Citation Index, Current Content, Emerging Source Citation Index, Scielo Citation Index de Clarivate Analytics), Scopus (Elsevier), Ulrich's Periodical Directory (ProQuest), EBSCO (Ebsco Industries Inc.), ProQuest, Sociological Abstracts (ProQuest), ELSEVIER, ERIH (European Reference Index for the Humanities de la European Science Foundation), Taylor \& Francis, SAGE , JSTOR, CABI (Centre for Agricultural Bioscience International), PubMed (Medline de la National Library of Medicine), Hispanic American Periodicals Index (HAPI de la Universidad de California), Handbook of Latin American Studies (HLAS de la biblioteca del congreso de EEUU), y Modern Language Association Bibliography (MLA)

En algunos casos, los registros no eran consistentes, existían repeticiones, ausencias o incluso información mal registrada. Frente a este panorama, se chequearon individualmente los casos problemáticos. La reconstrucción de un universo de revistas latinoamericanas en actividad nos permitió avanzar sobre un grupo de revistas que hasta el momento no habían sido estudiadas en esta envergadura. Por lo que, se decidió avanzar en el estudio estadístico a partir de este universo sin aplicar un muestreo estadístico para guiar la representatividad. La actividad de las revistas fue chequeada individualmente ya sea desde la visita a su sitio personal hasta con el contacto con su editor/a. Consideramos a una revista como activa si por lo menos publicó un número en el último año de estudio.

En relación a la clasificación disciplinar, tomamos como criterio la autoadscripción que está presente en las fichas de registro en la petición de su número ISSN o ISSN-L, en la postulación para su inclusión en alguna base indexadora o en su propia presentación en su sitio web oficial. Consideramos como parámetro general la distribución disciplinar propuesta por la UNESCO para construir las variables asociadas. 
2 La cantidad de revistas identificadas por períodos corresponde a la base de revistas científicas activas al año 2015-2017 construida para una investigación de mayor envergadura (Salatino, 2018a). Por tanto, son revistas activas en la actualidad con fecha de creación en esos períodos. Asimismo, con fines meramente ilustrativos no se tuvo en consideración la superposición de los años de inicio y finalización de los períodos y se tomó la decisión de generar una continuidad temporal.

3 En cuanto al registro de los datos asociados a las instituciones editoras consideramos el grado máximo de agregación. Por ejemplo, para el caso de la revista Millcayac: Centro de Publicaciones, Facultad de Ciencias Políticas y Sociales, Universidad Nacional de Cuyo; sólo se consignó Universidad Nacional de Cuyo.

4 Esto no implica que las publicaciones no sean importantes para el PROINCE o los concursos docentes en las universidades. Sino que los/as agentes encumbrados en las universidades nacionales acumulan su prestigio a través de otros aspectos que no tienen que ver estrictamente con las publicaciones (dedicación a docencia, gestión universitaria, extensión, compromiso institucional, etc.). 